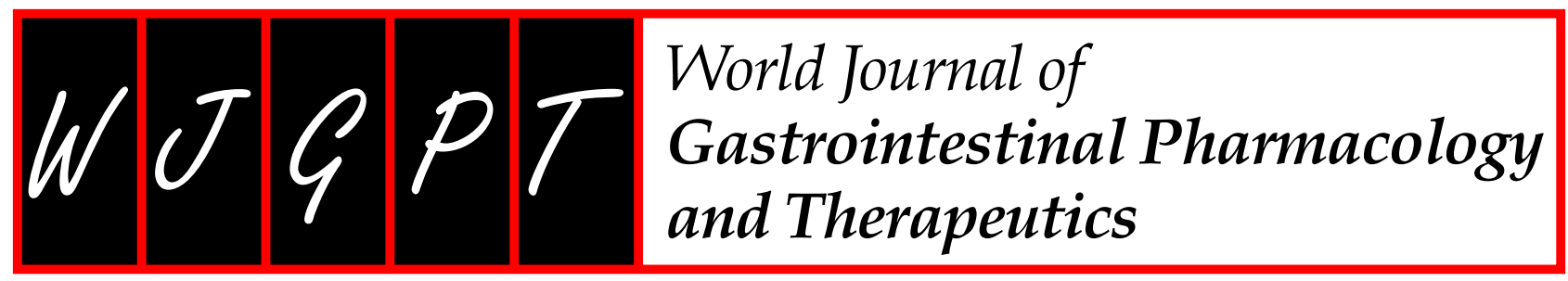

Online Submissions: http:/ / www.wjgnet.com/esps/

Help Desk: http:/ / www.wjgnet.com/esps/helpdesk.aspx

DOI: 10.4292/wjgpt.v5.i3.105

World J Gastrointest Pharmacol Ther 2014 August 6; 5(3): 105-112

ISSN 2150-5349 (online)

(C) 2014 Baishideng Publishing Group Inc. All rights reserved.

\title{
Diagnosis and treatment of gastroesophageal reflux disease
}

\author{
Raul Badillo, Dawn Francis
}

Raul Badillo, Dawn Francis, Division of Gastroenterology and Hepatology, Mayo Clinic Florida, Jacksonville, FL 32224, United States

Author contributions: Francis D and Badillo R solely contributed to this paper.

Correspondence to: Dawn Francis, MD, MHS, Division of Gastroenterology and Hepatology, Mayo Clinic Florida, Jacksonville, FL 32224, United States. francis.dawn@mayo.edu Telephone: +1-904-953-2814 Fax: +1-904-953-7366

Received: January 24, 2014 Revised: June 10, 2014

Accepted: June 20, 2014

Published online: August 6, 2014

\begin{abstract}
Gastroesophageal reflux disease (GERD) is a common disease with a prevalence as high as $10 \%-20 \%$ in the western world. The disease can manifest in various symptoms which can be grouped into typical, atypical and extra-esophageal symptoms. Those with the highest specificity for GERD are acid regurgitation and heartburn. In the absence of alarm symptoms, these symptoms can allow one to make a presumptive diagnosis and initiate empiric therapy. In certain situations, further diagnostic testing is needed to confirm the diagnosis as well as to assess for complications or alternate causes for the symptoms. GERD complications include erosive esophagitis, peptic stricture, Barrett's esophagus, esophageal adenocarcinoma and pulmonary disease. Management of GERD may involve lifestyle modification, medical therapy and surgical therapy. Lifestyle modifications including weight loss and/or head of bed elevation have been shown to improve esophageal $\mathrm{pH}$ and/or GERD symptoms. Medical therapy involves acid suppression which can be achieved with antacids, histamine-receptor antagonists or proton-pump inhibitors. Whereas most patients can be effectively managed with medical therapy, others may go on to require antireflux surgery after undergoing a proper pre-operative evaluation. The purpose of this review is to discuss the current approach to the diagnosis and treatment of gastroesophageal reflux disease.
\end{abstract}

(C) 2014 Baishideng Publishing Group Inc. All rights reserved.

Key words: Gastroesophageal reflux disease; Esophageal disease; Acid suppression; Fundoplication; Upper gastrointestinal tract disorder

Core tip: Given the high prevalence of gastroesophageal reflux disease (GERD) and the various complications which can result from inadequate treatment, it is important for practioners to have a proper understanding of the current approach to its diagnosis and management. Diagnostic tools including various methods of $\mathrm{pH}$ testing are discussed. Furthermore, it is important to understand the indications and contraindications to anti-reflux surgery in order to optimize our patient's surgical outcomes. Management of GERD in the obese patient may involve bariatric surgery and this is also further discussed.

Badillo R, Francis D. Diagnosis and treatment of gastroesophageal reflux disease. World J Gastrointest Pharmacol Ther 2014; 5(3): 105-112 Available from: URL: http://www.wjgnet.com/2150-5349/ full/v5/i3.105.htm DOI: http://dx.doi.org/10.4292/wjgpt.v5.i3.105

\section{SYMPTOMS AND EPIDEMIOLOGY}

Gastroesophageal reflux disease (GERD) is defined as symptoms or mucosal damage produced by the abnormal reflux of gastric contents into the esophagus or beyond, into the oral cavity (including larynx) or lung ${ }^{[1,2]}$. GERD can be classified as non-erosive reflux disease (NERD) or erosive reflux disease (ERD) based on the presence or absence of esophageal mucosal damage seen on endoscopy. The following document will provide a brief overview of the epidemiology, clinical symptoms and complications of GERD as well as a more comprehensive review of the current approach to diagnosis and management.

GERD is one of the most commonly encountered conditions by both primary care physicians and gastroen- 
Table 1 Symptoms of gastroesophageal reflux disease

\begin{tabular}{ll}
\hline Typical Symptoms & Acid regurgitation, heartburn \\
Atypical Symptoms & $\begin{array}{l}\text { Epigastric fullness, epigastric pressure, } \\
\text { epigastric pain, dyspepsia, nausea, } \\
\text { bloating, belching }\end{array}$ \\
Extraesophageal Symptoms & $\begin{array}{l}\text { Chronic cough, bronchospasm, } \\
\text { wheezing, hoarseness, sore throat, } \\
\text { asthma, laryngitis, dental erosions }\end{array}$ \\
\hline
\end{tabular}

terologists. To illustrate, a 2005 systematic review found the prevalence of GERD (defined by at least weekly heartburn and/or acid regurgitation) to be as high as $10 \%-20 \%$ in the Western world compared to a prevalence of less than 5\% in Asia. There is a trend for higher prevalence in North America compared to Europe, and a trend for higher prevalence in Northern over Southern Europe $^{[3]}$. It should be noted, however, that there are limitations in the diagnosis of GERD based solely on patient symptoms as there are patients with endoscopic evidence of GERD (e.g., esophagitis or Barrett's esophagus) who lack symptoms and patients who have symptoms but no objective evidence of GERD. The high prevalence of GERD in combination with the high cost of acid lowering medications results in the significant socioeconomic burden associated with the disease.

GERD can manifest in a wide range of symptoms which can be subdivided into typical, atypical and extraesophageal symptoms (Table 1). In general, symptoms tend to be more common after meals and are often aggravated by recumbency and relieved by acid lowering medications ${ }^{[1]}$. Typical symptoms include heartburn and acid regurgitation which have high specificity but low sensitivity for GERD ${ }^{[4]}$. Atypical symptoms such as epigastric pain, dyspepsia, nausea, bloating, and belching may be suggestive of GERD but may overlap with other conditions in the differential diagnosis such as peptic ulcer disease, achalasia, gastritis, dyspepsia and gastroparesis. Lastly, there are various extraesophageal symptoms including chronic cough, asthma, laryngitis and dental erosions $^{\left[{ }^{[}\right]}$. The current belief is that these symptoms are caused by either microaspiration of refluxate or a vagally mediated reflex triggered by distal esophageal acid exposure. The shared vagal innervation of the cough reflex and esophagus is believed to act as the pathway through which distal esophageal acid exposure may lead to coughing, a process known as the esophagobronchial reflex ${ }^{[6]}$. However, extraesophageal symptoms could be secondary to a host of other conditions and should not uniformly be attributed to a diagnosis of GERD, especially when typical symptoms are absent.

GERD symptoms have a profound impact on healthrelated quality of life (HRQoL). A 2011 systematic review of nine studies, including a total of 14774 patients with GERD, showed that persistent reflux symptoms on PPI therapy are associated with reduced physical and mental HRQoL, while reduced mental HRQoL at baseline seemed to impair symptomatic response to PPIs.
The authors recommended that one consider behavioral and psychological factors when making decisions about disease management in those patients with persistent reflux symptoms and reduced well-being despite PPI treatment $t^{[7]}$. It is therefore important to recognize, diagnose and properly treat patients with GERD in order to avoid detrimental effects on quality of life as well as numerous complications.

GERD-related complications include erosive esophagitis, peptic stricture, Barrett's esophagus, esophageal adenocarcinoma and pulmonary disease. Esophageal adenocarcinoma is thought to be more common in older white males with elevated body mass index and screening for Barrett's esophagus is recommended in this group ${ }^{[8,9]}$.

\section{DIAGNOSIS}

The diagnosis of GERD is typically made by a combination of clinical symptoms, response to acid suppression, as well as objective testing with upper endoscopy and esophageal $\mathrm{pH}$ monitoring. For example, the combination of moderate to severe typical symptoms and endoscopic changes (erosive esophagitis or Barrett's esophagus) are highly specific (97\%) for GERD (confirmed with $\mathrm{pH}$ testing ${ }^{[10]}$. However, a well-taken history alone can prove very valuable in the diagnosis, especially in the setting of heartburn and acid regurgitation which have a very high specificity ( $89 \%$ and $95 \%$, respectively), albeit low sensitivity $(38 \%$ and $6 \%)$ for GERD ${ }^{[4]}$. This can allow one to make a presumptive diagnosis and begin empiric therapy, thereby avoiding a comprehensive and costly evaluation in every patient presenting with uncomplicated symptoms ${ }^{[11]}$. Additional testing may be necessary, however, for those who do not respond to acid suppression, those who have alarm symptoms (e.g., dysphagia, odynophagia, iron deficiency anemia, weight loss, etc.) and those who have suffered from the disease for an extended period of time due to concern for Barrett's esophagus ${ }^{[1]}$. The rationale for pursuing additional testing includes confirmation of GERD as well as evaluation of GERD associated complications or alternate diagnoses (Table 2).

\section{Empirical therapy}

As mentioned above, those with a history suggestive of uncomplicated GERD manifesting in typical symptoms of heartburn and/or regurgitation can be offered empiric treatment (see treatment section). Typical symptoms that are responsive to acid suppression offer additional evidence for pathologic esophageal acid exposure and it is reasonable to assume a diagnosis of GERD in patients who respond to appropriate therapy ${ }^{[1]}$. On the other hand, typical symptoms that do not improve warrant further evaluation to demonstrate the existence of GERD and evaluate for an alternate diagnosis. Likewise, patients with atypical symptoms or non-cardiac chest pain as their primary complaint should also be considered for further diagnostic evaluation prior to empiric therapy. It should be remembered that a minority of patients on even high 


\begin{tabular}{ll}
\hline Diagnostic test & \\
\hline PPI trial & Classic GERD symptoms with no alarm symptoms. \\
Esophageal pH monitoring & Refractory symptoms where GERD diagnosis is in question, pre-operative evaluation for non-erosive disease \\
Upper endoscopy & Alarm symptoms (e.g., dysphagia), PPI unresponsive patients, high risk for Barrett's esophagus \\
Barium esophagram & Evaluation of dysphagia, otherwise not recommended for GERD evaluation \\
Esophageal manometry & Prior to anti-reflux surgery to rule out esophageal dysmotility (e.g., achalasia, scleroderma), otherwise not \\
& recommended for GERD evaluation
\end{tabular}

GERD: Gastroesophageal reflux disease; PPI: Proton pump inhibitor.

dose proton pump inhibition will continue to have objective evidence of pathologic esophageal acid exposure on ambulatory $\mathrm{pH}$ monitoring $^{[12]}$, likely a result of medication non-compliance or PPI resistance.

\section{Ambulatory pH monitoring}

Ambulatory reflux monitoring is the only modality allowing direct measurement of esophageal acid exposure, reflux episode frequency and association between symptoms and reflux episodes. It is typically used to evaluate patients with persistent symptoms despite medical therapy, particularly those without endoscopic evidence of GERD, in order to confirm the diagnosis. It can also be employed to monitor the control of reflux in those on therapy with persistent symptoms ${ }^{[1]}$ and is also recommended in endoscopy negative patients prior to undergoing anti-reflux surgery in order to confirm the diagnosis.

Reflux monitoring is typically performed using either a wireless capsule or a transnasal catheter $(\mathrm{pH}$ alone or combined $\mathrm{pH}$-impedance) with the patient either on or off acid suppression. Though there is no uniform consensus regarding the most optimal method, each has its advantages and disadvantages. For either study, diet and activity should remain unchanged in order to capture an accurate depiction of day to day esophageal acid exposure.

Wireless capsule decreases patient discomfort, allows for longer recording time, and may improve accuracy by allowing the patient to resume normal activities without the presence of a transnasal catheter. The test involves endoscopic or transnasal placement of a radiotelemetry $\mathrm{pH}$ sensing capsule to the mucosa of the distal esophagus. The capsule (conventionally placed $6 \mathrm{~cm}$ above the squamocolumnar junction) measures $\mathrm{pH}$ and transmits the data via a radiofrequency signal to a small receiver clipped onto the patient's belt ${ }^{[13]}$. Unlike with traditional catheter-based systems, this approach allows the patient to resume normal activity without the conspicuous presence of a transnasal catheter and also allows for additional recording time (typically $48 \mathrm{~h}$ compared to $24 \mathrm{~h}$ recording with catheter-based monitoring). Another advantage of wireless capsule is the fixed position of the capsule on the esophageal wall in comparison to catheter-based systems where migration due to swallowing or talking has been shown to occur ${ }^{[14,15]}$. Potential disadvantages include additional expense due to endoscopic placement (as na- sal passage can be difficult due to size of capsule), early detachment in a minority of patients, patient discomfort which could require removal via repeat endoscopy, as well as overdiagnosis of GERD due to ingestion of acidic foods ${ }^{[16]}$. There is also some data suggesting an increased number of reflux episodes during the first 6 hour period following propofol administration ${ }^{[17]}$.

Transnasal catheter $\mathrm{pH}$ testing is limited by patient tolerance and $24 \mathrm{~h}$ monitoring but has the unique advantage of adding impedance which allows distinguishing between acid and non-acid (weakly acidic or weakly alkaline) gastroesophageal reflux. Impedance monitoring detects changes in the resistance to electrical current across adjacent electrodes, allowing it to differentiate the antegrade and retrograde bolus transit of both liquids and gas. Due to the ability to detect both acid as well as nonacid reflux, impedance-pH monitoring has greater sensitivity than $\mathrm{pH}$ monitoring alone in the detection of gastroesophageal reflux $^{[18]}$. It is the test of choice for on-PPI testing, as these patients have lower rates of acidic reflux with continued episodes of weakly acidic reflux which can then be detected with this modality. In contrast, both wireless capsule and catheter-based systems can be used for evaluation of GERD in patients off acid suppression ${ }^{[19]}$.

Regardless of the $\mathrm{pH}$ monitoring system used, a symptom-reflux correlation is made using either the symptom index (SI) or symptom association probability (SAP), the latter being the preferred statistical calculation ${ }^{[20]}$. This allows for measurement of the strength of the association between reflux events and symptoms. A positive association combined with abnormal esophageal acid exposure provides evidence that symptoms are being caused by GERD.

\section{Upper endoscopy}

Upper endoscopy is the primary modality used in the evaluation of the esophageal mucosa in patients with GERD and also allows for biopsies of concerning lesions (e.g., Barrett's metaplasia, strictures or masses). It is important though to understand that there are limitations with the use of upper endoscopy in the diagnosis of GERD. For instance, while an endoscopy showing esophagitis or Barrett's esophagus essentially confirms the diagnosis of GERD (high specificity), a normal endoscopy does not refute the diagnosis. In fact, most patients with typical symptoms of GERD will have no endoscopic evidence 
of GERD on esophagogastroduodenoscopy. Therefore, an upper endoscopy is not required for the diagnosis and is mostly performed for evaluation of GERD associated complications and alternative diagnoses as well as for placement of wireless capsule $\mathrm{pH}$ probes. Patients with multiple risk factors for esophageal adenocarcinoma (age 50 years or older, male sex, white race, chronic GERD, hiatal hernia, elevated BMI, and intra-abdominal distribution of body fat) should receive screening endoscopy for Barrett's esophagus ${ }^{[8]}$.

\section{Barium esophagram}

Barium esophagram was once recommended as a screening test for GERD, but is no longer part of the diagnostic evaluation. A 1996 study of 125 patients compared barium esophagram to esophageal $\mathrm{pH}$ monitoring to assess the accuracy of barium screening as a predictor of abnormal esophageal acid exposure. A significantly greater degree of abnormal esophageal acid exposure occurred in patients who had a hiatal hernia or spontaneous reflux on barium radiography. However, the sensitivity and specificity of barium radiography for abnormal degrees of acid reflux were insufficient and therefore this test is no longer recommended in the diagnosis of GERD $^{[21]}$. On the other hand, it is frequently used in the evaluation of complications related to GERD (e.g., peptic stricture) as well as in the evaluation of dysphagia in the post anti-reflux surgery patient, in conjunction with endoscopic evaluation.

\section{Esophageal manometry}

Esophageal manometry is most useful for the evaluation of dysmotility and has only limited utility in the evaluation of GERD. Although disruption of the anti-reflux barrier (gastroesophageal junction) and dysfunction of esophageal peristalsis are common in GERD patients, these findings are not diagnostic and therefore there is no manometric pattern which is pathognomonic for reflux $^{[22]}$. The role of manometry in the evaluation of GERD remains limited to preoperative testing for exclusion of significant motility disorders such as achalasia or scleroderma (clear contraindications to anti-reflux surgery) as well as for assisting in proper positioning of transnasal $\mathrm{pH}$ probes. Otherwise, this test is not recommended for the diagnosis of GERD.

\section{TREATMENT}

GERD is a chronic disease that typically requires long term management in the form of lifestyle modification, medical therapy and, for a subset of patients, surgical therapy.

\section{Lifestyle changes}

Lifestyle and diet modification traditionally have included weight loss, head of bed elevation, avoidance of nighttime meals, and elimination of trigger foods such as chocolate, caffeine and alcohol. A 2006 systematic review of 16 randomized trials evaluated the impact of lifestyle measures on GERD and concluded that only weight loss and elevation of the head of the bed improved esophageal $\mathrm{pH}$ and/or GERD symptoms ${ }^{[23]}$. A 2006 systematic review and meta-analysis suggested a positive association between increasing BMI and the presence of GERD within the United States and possibly within other countries as well ${ }^{[24]}$. Interestingly, BMI was found to be associated with symptoms of GERD in both normal weight and overweight women and even moderate weight gain among those of normal weight was found to cause or exacerbate symptoms ${ }^{[25]}$. Therefore, weight loss is recommended for GERD patients who are overweight or who have had recent weight gain.

For nighttime reflux symptoms, patients should elevate the head of the bed and avoid recumbency $3 \mathrm{~h}$ postprandially. A recent study aimed to compare the recurrence rates of ERD and NERD, and determine the risk factors related to the recurrence. Recurrence was diagnosed when patients complained of GERD symptoms requiring additional medication after initial recovery with 4-8 wk of PPI treatment. The authors found that a shorter dinner-to-bedtime interval was the most significant factor influencing the recurrence of GERD and patients who usually slept within $3 \mathrm{~h}$ after eating had higher recurrence rates ${ }^{[2]}$. Despite strict compliance, lifestyle changes alone are frequently inadequate at controlling symptoms and medical therapy often becomes necessary.

\section{Medical therapy}

The mainstay of treatment of GERD is acid suppression which can be achieved with several classes of medications including antacids, histamine-receptor antagonists ( $\mathrm{H}_{2} \mathrm{RAs}$ ) or proton-pump inhibitors (PPIs). Studies have shown more complete healing of erosive esophagitis and heartburn relief with PPIs vs $\mathrm{H}_{2} \mathrm{RA}$ and this effect occurs nearly twice as fast (healing rate and heartburn relief of $11.7 \%$ /wk and $11.5 \%$ /wk vs $5.9 \%$ /wk and $6.4 \% /$ wk in the PPI and $\mathrm{H}_{2} \mathrm{RA}$ groups, respectively) ${ }^{[27]}$. Additionally, studies show that ERD is more difficult to treat with $\mathrm{H}_{2} \mathrm{RA}$ compared to PPIs ${ }^{[28]}$ and patients with ERD tend to have a higher symptom response to PPIs compared to their NERD counterparts ${ }^{[29]}$. Therefore, it is recommended to treat erosive reflux disease with maintenance PPI therapy at the lowest effective dose as most will relapse after discontinuation of therapy ${ }^{[30]}$. In general, PPIs are felt to be equally effective and patients should be instructed to take these medications $30-60 \mathrm{~min}$ prior to meals; the exception to this is dexlansoprazole which can be taken irrespective of food intake.

In contrast, patients with NERD may potentially be managed successfully with on-demand PPI or, alternatively, with less costly therapy such as $\mathrm{H}_{2}$ RAs. A 2001 study set out to determine the feasibility of step-down therapy in patients with symptoms of GERD rendered asymptomatic with PPIs. After 1 year follow up, 58\% of patients in the step-down group were asymptomatic on either non-PPI therapy or no therapy at all. Of those 


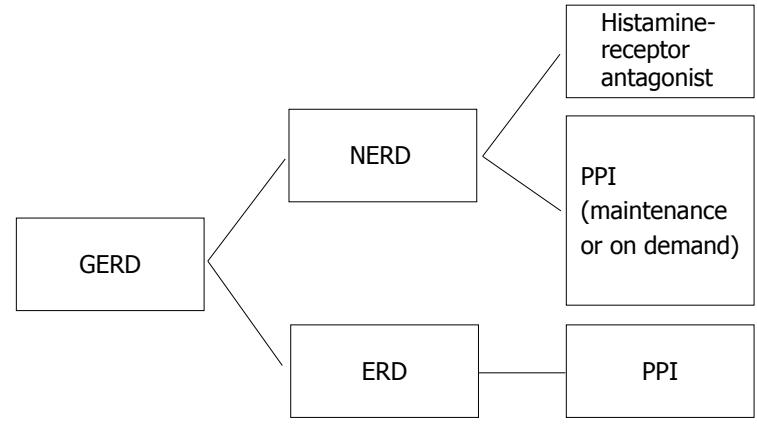

Figure 1 In general, patients with gastroesophageal reflux disease who are found to have evidence of erosive esophagitis on endoscopy should be placed on maintenance proton pump inhibitor due to the high risk of relapse off proton pump inhibitor. However, patients with NERD may achieve symptom control on $\mathrm{H}_{2} \mathrm{RAs}$ or, alternatively, with on-demand PPI. If symptoms persist, maintenance PPI should be considered. GERD: Gastroesophageal reflux disease; PPI: Proton pump inhibitor; ERD: Erosive reflux disease; NERD: Non-erosive reflux disease.

who remained off PPIs, 59\% required $\mathrm{H}_{2} \mathrm{RAs}^{[31]}$. Given the high cost associated with indefinite PPI use, attempts should be made to treat patients with the least expensive yet effective medication, particularly in patient with NERD who may be able to be maintained on $\mathrm{H}_{2} \mathrm{RAs}$ with control of symptoms. If symptoms recur, then maintenance PPI therapy should be reconsidered (Figure 1).

Patients with PPI-refractory GERD can be challenging to treat and are frequently referred to a gastroenterologist. First, compliance with medical therapy and proper dosing should be addressed. A study involving 10159 patients with Barrett's esophagus and 48965 GERD patients without Barrett's esophagus found that PPI prescriptions were filled by only $66.6 \%$ and $60.4 \%$ of patients with BE and GERD, respectively ${ }^{[32]}$. Given such high rates of noncompliance, an accurate history is important to obtain in order to avoid escalating therapy unnecessarily. If symptoms are truly refractory to proper medical therapy, the dosing can be increased or an alternate PPI can be used. Both methods may lead to further symptom improvement and both appear to be equally effective $^{[33]}$. If a patient has predominantly nighttime symptoms, more effective nocturnal acid suppression may be achieved with bid or nighttime dosing of PPIs ${ }^{[34]}$.

Another approach in the PPI-refractory patient involves the addition of nighttime $\mathrm{H}_{2} \mathrm{RAs}$ to bid PPI therapy for persistent nighttime symptoms. Though a contested issue, the benefit from this approach would likely be temporary as studies have shown that after 1 mo of uninterrupted $\mathrm{H}_{2} \mathrm{RA}$ therapy, gastric acidity returns to pre- $\mathrm{H}_{2} \mathrm{RA}$ levels ${ }^{[35]}$. Another well studied medication is the GABAb agonist baclofen which has been shown to reduce postprandial reflux events and acid exposure in normal individuals and in patients with GERD by inhibiting transient lower esophageal sphincter relaxations, thought to be the primary cause of reflux events ${ }^{[36]}$. Unfortunately, side effects often preclude continued use of this medication and include drowsiness (up to 63\%), dizziness $(5 \%-15 \%)$, weakness $(5 \%-15 \%)$, and fatigue $(2 \%-4 \%)^{[37]}$. In a recent randomized, cross-over trial it was shown that administering baclofen at bedtime decreases sleep related reflux events and markedly improves objective and subjective sleep parameters compared with placebo. Thus, baclofen appears to have potential benefit for GERD patients with persistent symptoms on PPI therapy, especially those who have persistent nighttime heartburn and sleep complaints ${ }^{[37]}$. Finally, with respect to prokinetic therapy, a recent study randomized patients into an omeprazole plus mosapride (5HT4 agonist) group and omeprazole plus placebo group and found that the addition of mosapride to omeprazole was no more effective at controlling reflux symptoms than omeprazole alone in patients with NERD ${ }^{[38]}$. Based on this and several other studies, there is no clear role for the use of prokinetic therapy in the treatment of GERD.

If symptoms persist after attempts at maximizing medical therapy, an evaluation for non-GERD etiologies should be undertaken. An upper endoscopy should be performed next and may reveal an abnormality such as persistent erosive esophagitis, eosinophilic esophagitis, or Barrett's esophagus in roughly $10 \%$ of patients in whom empiric PPI therapy fails ${ }^{[39]}$. The finding of esophagitis would support the diagnosis of GERD and point towards noncompliance or failure of medical therapy. Most times, the esophagus will appear endoscopically normal and these patients should be further evaluated with $\mathrm{pH}$ monitoring to confirm or refute the diagnosis of GERD. Confirming pathologic acid reflux with a positive symptom correlation would indicate PPI failure and need for escalation of medical therapy or consideration of surgical options. The absence of GERD in a patient with typical heartburn symptoms would suggest a diagnosis of functional heartburn ${ }^{[2]}$.

\section{Surgical therapy}

Surgical therapy is another treatment option for longterm therapy in patients with GERD and has become more appealing since the introduction of laparoscopic anti-reflux surgery. Indications for anti-reflux surgery, which typically include laparoscopic fundoplication or bariatric surgery, include unwillingness to remain on lifelong medical therapy, intolerance of medical therapy, medically refractory symptoms with evidence of GERD on endoscopy or $\mathrm{pH}$ monitoring, or GERD in the setting of a large hiatal hernia (Table 3).

Proper patient selection is critical to obtain the best possible surgical outcomes and it is imperative that there be objective documentation of GERD. Furthermore, it is well known that the highest surgical response is seen in those with typical symptoms who respond to a PPI or have abnormal $\mathrm{pH}$ testing with good symptom correlation. On the other hand, response rates to surgical intervention are lower in those with atypical or extraesophageal symptoms. To illustrate, one study showed that at 69 mo after laparoscopic fundoplication, the majority of patients maintained improvement or resolution of heart- 


\section{Table 3 Indications for anti-reflux surgery}

Unwillingness to remain on lifelong medical therapy Intolerance of medical therapy

Medically refractory symptoms with objective evidence of GERD

GERD in the setting of a large hiatal hernia

Medically refractory GERD in the setting of morbid obesity

GERD: Gastroesophageal reflux disease.

burn (90\%), regurgitation (92\%), and dysphagia (75\%) when compared to before surgery. However, the results were less satisfactory in patients with extraesophageal symptoms such as hoarseness $(69 \%)$ and cough $(69 \%)^{[40]}$. In addition to upper endoscopy and esophageal $\mathrm{pH}$ testing, a preoperative workup should include a barium esophagram and esophageal manometry to ensure that there is normal esophageal motility. The combined results of this testing can establish the presence of disease and assist with planning the operative approach ${ }^{[41]}$.

The short and medium term outcomes of laparoscopic anti-reflux surgery are quite good in terms of improving the typical symptoms of GERD ${ }^{[42]}$. However, in the long term it appears these results may diminish. During a follow-up period of 10 to 13 years, one study comparing long term outcomes in medical and surgical therapies for GERD found that $62 \%$ of surgical patients took anti-reflux medications on a regular basis, compared to $92 \%$ of medical patients. Anti-reflux surgery can be very effective but should not be advised with the expectation that patients will no longer take anti-secretory medications $^{[43]}$.

Complications from anti-reflux surgery include dysphagia of sufficient severity to require esophageal dilation in about $6 \%$ of patients treated with fundoplication surgery ${ }^{[4]}$ as well as a significant increase in flatulence and inability to belch (gas bloat syndrome). This potential for complications underscores the importance of carefully selecting patients for anti-reflux surgery in order to optimize outcomes.

Due to concern for complications associated with traditional fundoplication, sphincter augmentation using the LINX Reflux Management System was developed. The surgery involves the laparoscopic placement of a bracelet of titanium beads with magnetic cores around the LES which serves to augment the physiologic barrier to reflux without altering gastric anatomy. Studies show that at four years following LINX implantation, 87.5\% of patients were satisfied with their present condition, and $80 \%$ of patients were free from daily dependence on $\mathrm{PPIs}^{[45]}$

In view of the invasiveness of surgery, several endoscopic therapies for GERD have been attempted but due to inability to control GERD have been removed from the market. One of the latest endoscopic techniques for treatment of GERD is transoral incisionless fundoplication. A recent study showed that only a subgroup of patients experienced improved quality of life and reduced need for PPIs at 3 years follow-up, and an unacceptably high percentage of patients required additional medication or revisional laparoscopic fundoplication ${ }^{[46]}$. Additional studies in endoscopic therapy for GERD are ongoing.

Finally, when it comes to the obese patient with GERD, a different approach should be considered. Gastric bypass is the recommended treatment for GERD in the morbidly obese patient (BMI $>35 \mathrm{~kg} / \mathrm{m}^{2}$ ) due to concerns over higher failure rates following Nissen fundoplication in this population. Not only does bariatric surgery better address the mechanisms that lead to GERD in obese patients with the potential for a more durable response, but it also reduces obesity-related comorbidities and possibly reduces the long-term mortality risk associated with morbid obesity in an acceptably safe, minimally-invasive, and cost-effective manner ${ }^{[4]}$. Although all common bariatric procedures improve GERD, Roux- en-Y gastric bypass is superior to adjustable gastric banding and sleeve gastrectomy ${ }^{[48]}$.

\section{REFERENCES}

1 DeVault KR, Castell DO. Updated guidelines for the diagnosis and treatment of gastroesophageal reflux disease. Am J Gastroenterol 2005; 100: 190-200 [PMID: 15654800 DOI: 10.1111/j.1572-0241.2005.41217.x]

2 Katz PO, Gerson LB, Vela MF. Guidelines for the diagnosis and management of gastroesophageal reflux disease. Am J Gastroenterol 2013; 108: 308-328; quiz 329 [PMID: 23419381 DOI: 10.1038/ajg.2012.444]

3 Dent J, El-Serag HB, Wallander MA, Johansson S. Epidemiology of gastro-oesophageal reflux disease: a systematic review. Gut 2005; 54: 710-717 [PMID: 15831922 DOI: 10.1136/ gut.2004.051821]

4 Klauser AG, Schindlbeck NE, Müller-Lissner SA. Symptoms in gastro-oesophageal reflux disease. Lancet 1990; 335: 205-208 [PMID: 1967675 DOI: 10.1016/0140-6736(90)902 87-F]

5 Hom C, Vaezi MF. Extra-esophageal manifestations of gastroesophageal reflux disease: diagnosis and treatment. Drugs 2013; 73: 1281-1295 [PMID: 23881666 DOI: 10.1007/ s40265-013-0101-8]

6 Smith JA, Abdulqawi R, Houghton LA. GERD-related cough: pathophysiology and diagnostic approach. Curr Gastroenterol Rep 2011; 13: 247-256 [PMID: 21465223 DOI: 10.1007/s11894-011-0192-x]

7 Becher A, El-Serag H. Systematic review: the association between symptomatic response to proton pump inhibitors and health-related quality of life in patients with gastro-oesophageal reflux disease. Aliment Pharmacol Ther 2011; 34: 618-627 [PMID: 21770991 DOI: 10.1111/j.1365-2036.2011.04774.x]

8 Spechler SJ, Sharma P, Souza RF, Inadomi JM, Shaheen NJ. American Gastroenterological Association medical position statement on the management of Barrett's esophagus. Gastroenterology 2011; 140: 1084-1091 [PMID: 21376940 DOI: 10.1053/j.gastro.2011.01.030]

9 Lagergren J, Bergström R, Nyrén O. Association between body mass and adenocarcinoma of the esophagus and gastric cardia. Ann Intern Med 1999; 130: 883-890 [PMID: 10375336 DOI: 10.7326/0003-4819-130-11-199906010-00003]

10 Tefera L, Fein M, Ritter MP, Bremner CG, Crookes PF, Peters JH, Hagen JA, DeMeester TR. Can the combination of symptoms and endoscopy confirm the presence of gastro- 
esophageal reflux disease? Am Surg 1997; 63: 933-936 [PMID: 9322676]

11 Giannini EG, Zentilin P, Dulbecco P, Vigneri S, Scarlata P, Savarino V. Management strategy for patients with gastroesophageal reflux disease: a comparison between empirical treatment with esomeprazole and endoscopy-oriented treatment. Am J Gastroenterol 2008; 103: 267-275 [PMID: 18289194 DOI: 10.1111/j.1572-0241.2007.01659.x]

12 Katzka DA, Paoletti V, Leite L, Castell DO. Prolonged ambulatory $\mathrm{pH}$ monitoring in patients with persistent gastroesophageal reflux disease symptoms: testing while on therapy identifies the need for more aggressive anti-reflux therapy. Am J Gastroenterol 1996; 91: 2110-2113 [PMID: 8855731]

13 Pandolfino JE, Vela MF. Esophageal-reflux monitoring. Gastrointest Endosc 2009; 69: 917-930, 930.e1 [PMID: 19249037 DOI: 10.1016/j.gie.2008.09.022]

14 Kwiatek MA, Pandolfino JE. The Bravo $\mathrm{pH}$ capsule system. Dig Liver Dis 2008; 40: 156-160 [PMID: 18096447 DOI: 10.1016/j.dld.2007.10.025]

15 Aksglaede K, Funch-Jensen P, Thommesen P. Intra-esophageal $\mathrm{pH}$ probe movement during eating and talking. A videoradiographic study. Acta Radiol 2003; 44: 131-135 [PMID: 12694094 DOI: 10.1034/j.1600-0455.2003.00033.x]

16 Agrawal A, Tutuian R, Hila A, Freeman J, Castell DO. Ingestion of acidic foods mimics gastroesophageal reflux during pH monitoring. Dig Dis Sci 2005; 50: 1916-1920 [PMID: 16187197 DOI: $10.1007 /$ s10620-005-2961-6]

17 Chawla A, Girda E, Walker G, Turcotte Benedict F, Tempel M, Morganstern J. Effect of Propofol on Acid Reflux Measured with the Bravo pH Monitoring System. ISRN Gastroenterol 2013; 2013: 605931 [PMID: 23691337 DOI: 10.1155/2013/605931]

18 Hirano I, Richter JE. ACG practice guidelines: esophageal reflux testing. Am I Gastroenterol 2007; 102: 668-685 [PMID: 17335450 DOI: $10.1111 / j .1572-0241.2006 .00936 . x]$

19 Ravi K, Francis DL. New technologies to evaluate esophageal function. Expert Rev Med Devices 2007; 4: 829-837 [PMID: 18035949 DOI: $10.1586 / 17434440.4 .6 .829]$

20 Weusten BL, Roelofs JM, Akkermans LM, Van Berge-Henegouwen GP, Smout AJ. The symptom-association probability: an improved method for symptom analysis of 24-hour esophageal pH data. Gastroenterology 1994; 107: 1741-1745 [PMID: 7958686]

21 Johnston BT, Troshinsky MB, Castell JA, Castell DO. Comparison of barium radiology with esophageal $\mathrm{pH}$ monitoring in the diagnosis of gastroesophageal reflux disease. Am J Gastroenterol 1996; 91: 1181-1185 [PMID: 8651167]

22 DeVault K, McMahon BP, Celebi A, Costamagna G, Marchese M, Clarke JO, Hejazi RA, McCallum RW, Savarino V, Zentilin P, Savarino E, Thomson M, Souza RF, Donohoe CL, O'Farrell NJ, Reynolds JV. Defining esophageal landmarks, gastroesophageal reflux disease, and Barrett's esophagus. Ann N Y Acad Sci 2013; 1300: 278-295 [PMID: 24117649 DOI: 10.1111/nyas.12253]

23 Kaltenbach T, Crockett S, Gerson LB. Are lifestyle measures effective in patients with gastroesophageal reflux disease? An evidence-based approach. Arch Intern Med 2006; 166: 965-971 [PMID: 16682569 DOI: 10.1001/archinte.166.9.965]

24 Corley DA, Kubo A. Body mass index and gastroesophageal reflux disease: a systematic review and meta-analysis. Am J Gastroenterol 2006; 101: 2619-2628 [PMID: 16952280 DOI: 10.1111/j.1572-0241.2006.00849.x]

25 Jacobson BC, Somers SC, Fuchs CS, Kelly CP, Camargo CA. Body-mass index and symptoms of gastroesophageal reflux in women. N Engl J Med 2006; 354: 2340-2348 [PMID: 16738270 DOI: 10.1056/NEJMoa054391]

26 Yang JH, Kang HS, Lee SY, Kim JH, Sung IK, Park HS, Shim CS, Jin CJ. Recurrence of gastroesophageal reflux disease correlated with a short dinner-to-bedtime interval. J Gastroenterol Hepatol 2014; 29: 730-735 [PMID: 24224689 DOI: 10.1111/jgh.12455]

27 Chiba N, De Gara CJ, Wilkinson JM, Hunt RH. Speed of healing and symptom relief in grade II to IV gastroesophageal reflux disease: a meta-analysis. Gastroenterology 1997; 112: 1798-1810 [PMID: 9178669 DOI: 10.1053/gast.1997.v112. pm9178669]

28 Bate CM, Keeling PW, O'Morain C, Wilkinson SP, Foster DN, Mountford RA, Temperley JM, Harvey RF, Thompson DG, Davis M. Comparison of omeprazole and cimetidine in reflux oesophagitis: symptomatic, endoscopic, and histological evaluations. Gut 1990; 31: 968-972 [PMID: 2210463 DOI: 10.1136/gut.31.9.968]

29 Dean BB, Gano AD, Knight K, Ofman JJ, Fass R. Effectiveness of proton pump inhibitors in nonerosive reflux disease. Clin Gastroenterol Hepatol 2004; 2: 656-664 [PMID: 15290657 DOI: 10.1016/S1542-3565(04)00288-5]

30 Vigneri S, Termini R, Leandro G, Badalamenti S, Pantalena M, Savarino V, Di Mario F, Battaglia G, Mela GS, Pilotto A. A comparison of five maintenance therapies for reflux esophagitis. N Engl J Med 1995; 333: 1106-1110 [PMID: 7565948 DOI: 10.1056/ NEJM199510263331703]

31 Inadomi JM, Jamal R, Murata GH, Hoffman RM, Lavezo LA, Vigil JM, Swanson KM, Sonnenberg A. Step-down management of gastroesophageal reflux disease. Gastroenterology 2001; 121: 1095-1100 [PMID: 11677201 DOI: 10.1053/ gast.2001.28649]

32 El-Serag HB, Fitzgerald S, Richardson P. The extent and determinants of prescribing and adherence with acid-reducing medications: a national claims database study. Am J Gastroenterol 2009; 104: 2161-2167 [PMID: 19568229 DOI: 10.1038/ ajg.2009.312]

33 Fass R, Sontag SJ, Traxler B, Sostek M. Treatment of patients with persistent heartburn symptoms: a double-blind, randomized trial. Clin Gastroenterol Hepatol 2006; 4: 50-56 [PMID: 16431305 DOI: 10.1016/S1542-3565(05)00860-8]

34 Hatlebakk JG, Katz PO, Kuo B, Castell DO. Nocturnal gastric acidity and acid breakthrough on different regimens of omeprazole $40 \mathrm{mg}$ daily. Aliment Pharmacol Ther 1998; 12: 1235-1240 [PMID: 9882032 DOI: 10.1046/j.1365-2036.1998.00426.x]

35 Fackler WK, Ours TM, Vaezi MF, Richter JE. Long-term effect of H2RA therapy on nocturnal gastric acid breakthrough Gastroenterology 2002; 122: 625-632 [PMID: 11874994 DOI: 10.1053/gast.2002.31876]

36 Zhang Q, Lehmann A, Rigda R, Dent J, Holloway RH. Control of transient lower oesophageal sphincter relaxations and reflux by the GABA(B) agonist baclofen in patients with gastro-oesophageal reflux disease. Gut 2002; 50: 19-24 [PMID: 11772961 DOI: 10.1136/gut.50.1.19]

37 Orr WC, Goodrich S, Wright S, Shepherd K, Mellow M. The effect of baclofen on nocturnal gastroesophageal reflux and measures of sleep quality: a randomized, cross-over trial. Neurogastroenterol Motil 2012; 24: 553-559, e253 [PMID: 22404184 DOI: 10.1111/j.1365-2982.2012.01900.x]

38 Miwa H, Inoue K, Ashida K, Kogawa T, Nagahara A, Yoshida S, Tano N, Yamazaki Y, Wada T, Asaoka D, Fujita $\mathrm{T}$, Tanaka J, Shimatani T, Manabe N, Oshima T, Haruma $\mathrm{K}$, Azuma T, Yokoyama T. Randomised clinical trial: efficacy of the addition of a prokinetic, mosapride citrate, to omeprazole in the treatment of patients with non-erosive reflux disease - a double-blind, placebo-controlled study. Aliment Pharmacol Ther 2011; 33: 323-332 [PMID: 21118395 DOI: $10.1111 / j .1365-2036.2010 .04517 . x]$

39 Poh CH, Gasiorowska A, Navarro-Rodriguez T, Willis MR, Hargadon D, Noelck N, Mohler J, Wendel CS, Fass R. Upper GI tract findings in patients with heartburn in whom proton pump inhibitor treatment failed versus those not receiving antireflux treatment. Gastrointest Endosc 2010; 71: 28-34 [PMID: 19922918 DOI: 10.1016/j.gie.2009.08.024]

40 Oelschlager BK, Quiroga E, Parra JD, Cahill M, Polissar N, Pellegrini CA. Long-term outcomes after laparoscopic antireflux surgery. Am J Gastroenterol 2008; 103: 280-287; quiz 288 [PMID: 17970835 DOI: 10.1111/j.1572-0241.2007.01606.x] 
41 Jobe BA, Richter JE, Hoppo T, Peters JH, Bell R, Dengler WC, DeVault K, Fass R, Gyawali CP, Kahrilas PJ, Lacy BE, Pandolfino JE, Patti MG, Swanstrom LL, Kurian AA, Vela MF, Vaezi M, DeMeester TR. Preoperative diagnostic workup before antireflux surgery: an evidence and experiencebased consensus of the Esophageal Diagnostic Advisory Panel. J Am Coll Surg 2013; 217: 586-597 [PMID: 23973101 DOI: 10.1016/j.jamcollsurg.2013.05.023]

42 Rickenbacher N, Kötter T, Kochen MM, Scherer M, Blozik E. Fundoplication versus medical management of gastroesophageal reflux disease: systematic review and meta-analysis. Surg Endosc 2014; 28: 143-155 [PMID: 24018760 DOI: 10.1007/ s00464-013-3140-z]

43 Spechler SJ, Lee E, Ahnen D, Goyal RK, Hirano I, Ramirez F, Raufman JP, Sampliner R, Schnell T, Sontag S, Vlahcevic ZR, Young R, Williford W. Long-term outcome of medical and surgical therapies for gastroesophageal reflux disease: follow-up of a randomized controlled trial. JAMA 2001; 285: 2331-2338 [PMID: 11343480 DOI: 10.1001/jama.285.18.2331]

44 Dominitz JA, Dire CA, Billingsley KG, Todd-Stenberg JA. Complications and antireflux medication use after antireflux surgery. Clin Gastroenterol Hepatol 2006; 4: 299-305 [PMID:
16527692 DOI: 10.1016/j.cgh.2005.12.019]

45 Bonavina L, Saino G, Lipham JC, Demeester TR. LINX(®) Reflux Management System in chronic gastroesophageal reflux: a novel effective technology for restoring the natural barrier to reflux. Therap Adv Gastroenterol 2013; 6: 261-268 [PMID: 23814607 DOI: 10.1177/1756283X13486311]

46 Witteman BP, Strijkers R, de Vries E, Toemen L, Conchillo JM, Hameeteman W, Dagnelie PC, Koek GH, Bouvy ND. Transoral incisionless fundoplication for treatment of gastroesophageal reflux disease in clinical practice. Surg Endosc 2012; 26: 3307-3315 [PMID: 22648098 DOI: 10.1007/ s00464-012-2324-2]

47 Prachand VN, Alverdy JC. Gastroesophageal reflux disease and severe obesity: Fundoplication or bariatric surgery? World J Gastroenterol 2010; 16: 3757-3761 [PMID: 20698037 DOI: 10.3748/wjg.v16.i30.3757]

48 Pallati PK, Shaligram A, Shostrom VK, Oleynikov D, McBride CL, Goede MR. Improvement in gastroesophageal reflux disease symptoms after various bariatric procedures: Review of the Bariatric Outcomes Longitudinal Database. Surg Obes Relat Dis 2014; 10: 502-507 [PMID: 24238733 DOI: 10.1016/j.soard.2013.07.018]

P- Reviewer: Clayton SB, Hoff DAL, Lai YC S- Editor: Wen LL L- Editor: A E- Editor: Lu YJ 


\section{DS \\ Baishideng ${ }^{\circledR}$}

Published by Baishideng Publishing Group Inc

8226 Regency Drive, Pleasanton, CA 94588, USA

Telephone: +1-925-223-8242

Fax: +1-925-223-8243

E-mail: bpgoffice@wignet.com

Help Desk: http://www.wjgnet.com/esps/helpdesk.aspx

http://www.wjgnet.com

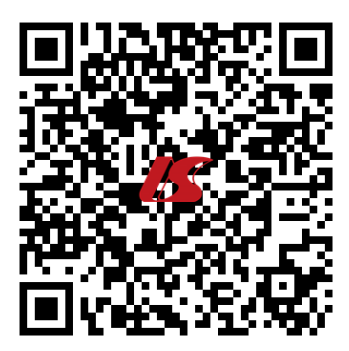

